\title{
Untangling the untamed spiritual root of disease
}

\author{
Author: Adewale ] Alegbeleye
}

\section{Aims}

To highlight the need for taking cognisance of the spiritual roots of certain diseases of unknown aetiologies among healthcare professionals. To present the valuable new health innovation: The $6 \mathrm{D}$ of Health Model.

\section{Methods}

The burden of chronic disease is a global challenge. The World Health Organization (WHO) has warned that the world is currently facing a crisis of chronic diseases due to their major adverse impacts. In 2016, about 15 million people in England were living with a long-term condition. These cause premature death and create large adverseand underappreciated - economic effects on families, communities and societies in general.

My inspiration and my personal pursuit of this issue over the past 7 years has led me to believe that there are better outcomes for these categories of diseases when combined medical and spiritual interventions are provided for patients by people with the right expertise. Science is only able to understand human beings as physical beings, rather than a combination of body, soul and spirit. This is because major scientific research in the medical field has mainly focused on discovery at a physical level alone.

\section{Results}

Harold Koenig found that at least 326 quantitative, peer-reviewed studies had examined relationships between spirituality and wellbeing. Of those, he found significant positive associations in 256 (79\%) studies. According to Lifesitenews.com, more than 500 physicians from 26 countries gathered for a conference yearly, in which medical doctors from around the world presented scientific evidence of divine healing.

\section{Conclusions}

Following the analysis of my results, I can conclude that this is an area that has been overlooked over centuries. I discovered that certain severe diseases as well as those of unknown aetiology are not amenable to treatment and may have epigenetic, or more precisely, spiritual roots. This is a vital element that is not currently taken actively into consideration during treatment but could help a lot of patients, especially those with chronic diseases.

Author: Basildon and Thurrock University Hospitals NHS Foundation Trust, Essex, UK
I have used spiritual intervention with credible results for several patients with various ailments. There was substantial observable evidence that this is an interesting subject. However, it calls for a form of further qualitative research exploration.

On the dimension of health, I also explored the domains of health - physical, family, social, emotional, mental and spiritual. The $6 \mathrm{D}$ of Health model is a new innovation that would be a valuable concept to empower people on preventative health and restoration. This new model is described in my book called The $6 D$ of Health.

The clinical implication is that in the future, if applied appropriately, patients could have better outcomes, quicker length of stay, significant reduction in healthcare costs and reduction in the burden of chronic diseases worldwide.

\section{Conflict of interest statement}

I do not have a conflict of interest, though $6 \mathrm{D}$ of Health is a registered IPO of Aleye Limited. 